\title{
Synthetic Vaccines from Tumor-Associated Glycopeptide Antigens
}

\author{
Ulrika Westerlind ${ }^{\star a}$ and Horst Kunz ${ }^{\mathrm{b}}$
}

\begin{abstract}
The aberrantly glycosylated and extensively over-expressed membrane-bound mucin MUC1 glycoprotein forms a tumor specific epitope on the surface of epithelial cells. Using defined synthetic glycopeptide structures consisting of the MUC1 tandem repeat region for immunization, antibodies selectively binding to tumor cell surface should be induced. Recent examples of synthetic vaccines directed against the $O$-glycosylated MUC1 tandem repeats and their immunological evaluation will be given here. These include synthetic MUC1 glycopeptides conjugated to immunostimulants, such as T-cell peptide epitopes, immune carrier proteins or lipid immunostimulants.
\end{abstract}

Keywords: Antibodies · Antigens · Glycobiology · Glycopeptides · Glycosylated amino acids · Immunology · Solid phase synthesis · Vaccines

\section{Introduction}

In 1984, Springer published that epithelial tumor cells expose glycoproteins on outer cell-membranes which show an altered glycosylation pattern consisting of $\mathrm{T}$ - and precursor $\mathrm{T}_{\mathrm{N}}$ antigen structures. ${ }^{[1]}$ Mucins are a class of extensively glycosylated proteins expressed on the surface of epithelial cells or secreted to function in mucus. They normally carry long complex $O$-linked carbohydrate structures that obscure the protein core. The membranebound glycoprotein mucin 1 (MUC1) is the most intensively studied mucin protein with regard to cancer immunotherapy. ${ }^{[2]}$ The extracellular domain has a structural feature common to all mucins consisting

\footnotetext{
${ }^{\star}$ Correspondence: Dr. U. Westerlind ${ }^{a}$ a Gesellschaft zur Förderung der Analytischen Wissenschaften e.V.

ISAS - Leibniz Institute for Analytical Sciences Otto-Hahn-Str. 6b, D-44227 Dortmund, Germany Tel.: +492311392 4215

Fax: +4923113924850

E-mail: ulrika.westerlind@isas.de

bJohannes Gutenberg-Universität Mainz

Institut für Organische Chemie

Duesbergweg 10-14, D-55128 Mainz, Germany

E-mail: hokunz@uni-mainz.de
}

of a region formed by a variable number of tandem repeats (VNTR). In MUC1, the VNTR region consists of 20-125 tandem repeats of 20 amino acids of the sequence HGVTSAPDTRPAPGSTAPPA. ${ }^{[3]}$ Each repeat includes five potential $O$-glycosylation sites (underlined). On epithelial tumor cells, MUC1 is extensively overexpressed and its glycosylation pattern is altered. Concomitant down-regulation of glycosyltransferases, in particular of the core $2 \beta-1,6-N$-acetylglucosaminyltransferase, and up-regulation of sialyltransferases results in short saccharides (underglycosylation) often with premature sialylation. ${ }^{[4]}$ The $\mathrm{T}_{\mathrm{N}}, \mathrm{T}$, sialyl- $\mathrm{T}_{\mathrm{N}},(2,3)$-sialyl-T and (2,6)-sialyl-T structures constitute of such important tumor-associated saccharide antigens (Fig. 1).

By induction of antibodies specific against the MUC1 tumor-associated antigens, it should be possible to break the tolerance of the immune system. However, additional stimulation of the naive $\mathrm{B}$ cell by activated $\mathrm{CD}^{+} \mathrm{T}$ helper cells is required for the differentiation into an antibody-secreting plasma cell which produces the humoral immune response based on an immunological memory. The naïve $\mathrm{T}$ helper $\left(T_{H}\right)$ cells are activated when their $T$ cell receptor (TCR) binds to the T cell peptide epitope presented by the major histocompatibility complex II (MHC II) on the surface of a antigen-presenting cell (APC). The peptide epitope presented by the APCs has to be generated by proteolytic fragmentation of the extracellular antigen (vaccine) that has been recognized by the APC receptor and internalized via endocytosis. When the proteolytically cleaved fragments contain the suitable sequences they can either be presented by the MHC class I proteins generating cytotoxic T-cell activation or by the MHC class II proteins generating $\mathrm{T}$ helper cell activation. ${ }^{[5]}$

Owing to the moderate immunogenicity of tumor-associated MUC1 glycopeptides, these compounds need to be coupled to carrier proteins, e.g. bovine serum albumin (BSA) or keyhole limplet hemocyanine (KLH), or they must be combined with immuno-stimulating $\mathrm{T}_{\mathrm{H}}$-cell peptides, for example from ovalbumin. ${ }^{[6]}$ In addition, immunization using these vaccines also requires the support by an adjuvant, for example Freund's adjuvant. Alternatively, Pam ${ }_{3}$ Cys lipopeptides which are ligands to Toll-like receptors have been applied as built-in adjuvant. ${ }^{[7]}$

\section{Strategies for Preparation of $T_{N}$, $\mathrm{T}$, Sialyl $\mathrm{T}_{\mathrm{N}}$, Sialyl T Glycopeptides and Vaccines}

MUC1 tandem repeat glycopeptides are synthesized on solid-phase according to the Fmoc strategy using glycosylated amino acid building blocks. The chemical synthesis of glycosylated Fmoc-serine and threonine building blocks is a demanding task. The tumor epitope glycosyl amino acids can be obtained from the $\mathrm{T}_{\mathrm{N}}$-antigen intermediate by a unifying biomimetic strategy (Fig. 2). Exploiting the relatively high reactivity of the 6- and 3-hydroxyl groups of galactose in combination with proper protecting groups, regioselective glycosylations were achieved affording the 2,6-sialyl Tn, 2,6-sialyl-T and 2,3-sialyl-T Fmoc-amino acid building blocks, respectively[6a] (Fig. 2).

As illustrated in Scheme 1, solid-phase glycopeptide synthesis was performed using Fmoc amino acids and Fmoc glycosyl amino acid building blocks in a stepwise 


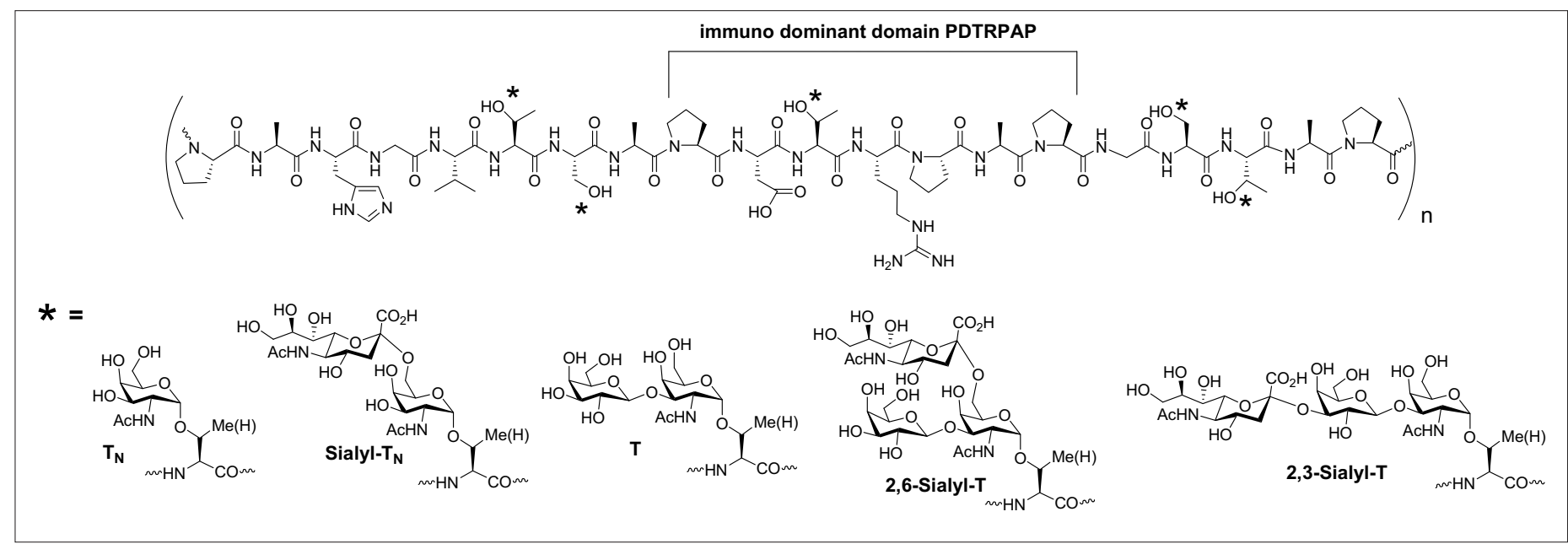

Fig. 1. Tumor-associated glycosylation on MUC1 tandem repeat peptides.

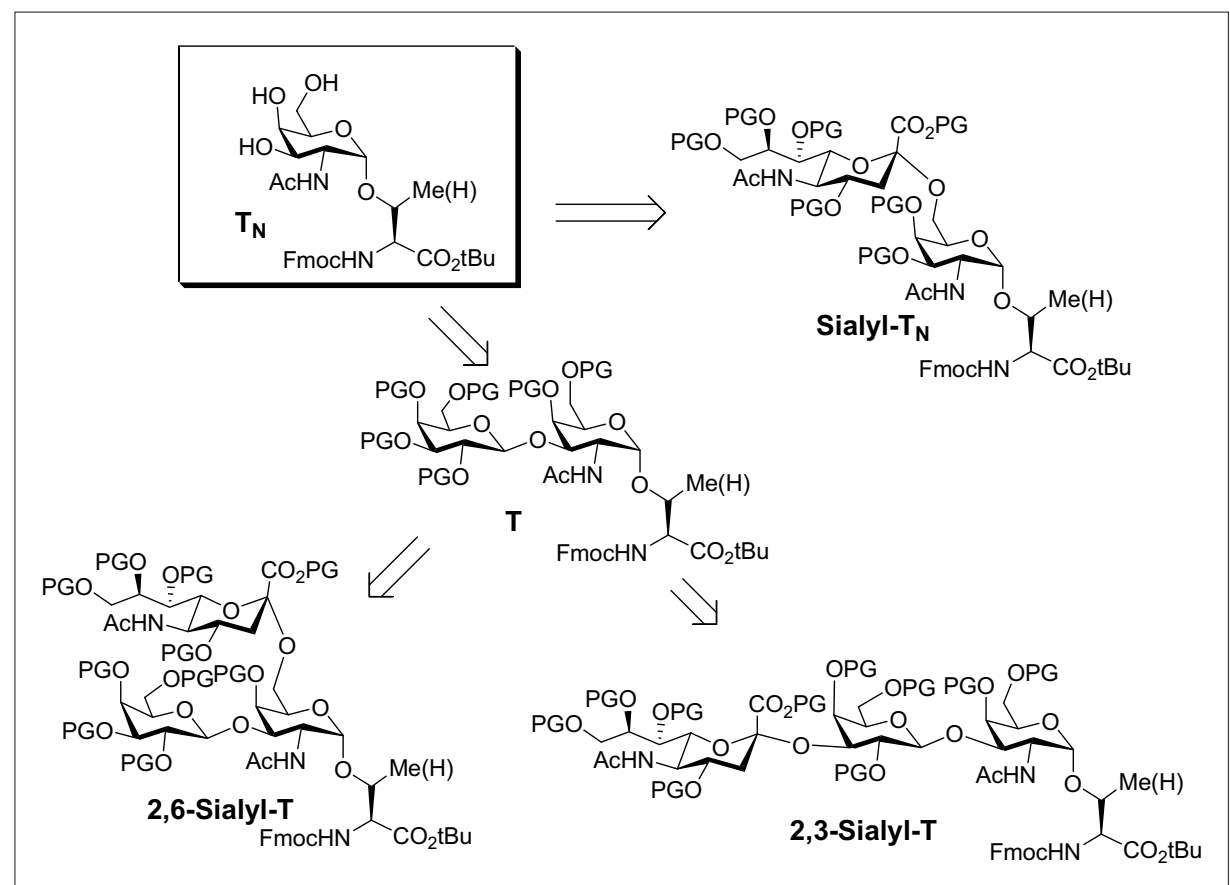

Fig. 2. Synthetic strategy for glycosylated amino acid building blocks.

fashion, starting with a resin preloaded with the $C$-terminal amino acid. The choice of resin depends on whether the glycopeptides have to be obtained with intact amino acid side chain protecting groups or without side chain protection. For mild selective cleavage of the anchor, the trityl resin cleavable by $0.1 \%$ TFA or a resin with the 2-phenyl-2-trimethylsilyl ethyl ester (PTMSEL) linker cleavable with tetrabutylammonium fluoride (TBAF) can be used. An alternative linker is the allylic HYCRON linker, which is cleavable by palladium(0)-catalyzed allyl transfer. If the side chain protective groups have to be simultaneously removed from the peptide during cleavage, the Wang resin is most commonly used. It is cleaved with a $95 \%$ TFA mixture. ${ }^{[8]}$ The choice of resin is also dependent on the peptide sequence. If the C-terminal sequence is prone to diketopiperazine formation, such as alanyl-proline, a bulky anchor is required, for example the trityl linker or the fluoride-sensitive PTMSEL linker. The glycosylated amino acid building blocks are often coupled manually using 1.5-2 equivalents and activated with the more reactive HATU/HOAt reagent, while the Fmoc amino acids are usually coupled automatically in a peptide synthesizer using 5-20 equivalents and standard HBTU/HOBt reagents. ${ }^{[9]}$ After cleavage from resin and purification through HPLC, the glycopeptides are either conjugated to an immunostimulant or further deprotected within the glycan portion and then conjugated. Deprotection of the glycans is performed by initial catalytic hydroge- nation of the sialic acid benzyl ester followed by removal of the $O$-acetyl protective groups through mild transesterification in methanol with catalytic amounts of $\mathrm{NaOMe}$ at $\mathrm{pH}$ 9-9.5 methanol or using hydrazine hydrate in methanol.[10,11]

\section{MUC1 Glycopeptides Conjugated to a Peptide T-Cell Epitope}

Synthesized sialyl- $\mathrm{T}_{\mathrm{N}}$ and $\mathrm{T}_{\mathrm{N}}$ monodi- and triglycosylated 38 amino acid MUC1 tandem repeat peptides connected to an $\mathrm{OVA}_{323-339}$ T-cell peptide epitope via a non-immunogenic spacer are examples of synthetic T-cell epitope glycopeptide vaccines $^{[12 a]}$ (Fig. 3). The vaccines were prepared by Fmoc solid-phase peptide synthesis. The vaccine constructs in combination with complete Freund's adjuvant (CFA) were used for immunization of transgenic mice whose $\mathrm{T}$ cells express an OVA-specific CD4 receptor. After the third immunization, high antibody titers were displayed in one of three mice, immunized with the monoglycosylated vaccine $\mathbf{1}$ and in two of three mice immunized with the diglycosylated vaccine 2 . In contrast, none of the mice immunized with the triglycosylated vaccine $\mathbf{3}$, with additional glycosylation in the immuno dominant PDTR domain generated an immune response. The antibodies generated from the first two vaccines were further analyzed by ELISA and microarray binding specificity studies confirming a high specificity to the immunized glycopeptide epitopes ${ }^{[12]}$ (Fig. 3).

\section{MUC1 Glycopeptides Conjugated to Carrier Proteins}

Vaccines consisting of protein carrier conjugates such as BSA or KLH conju- 


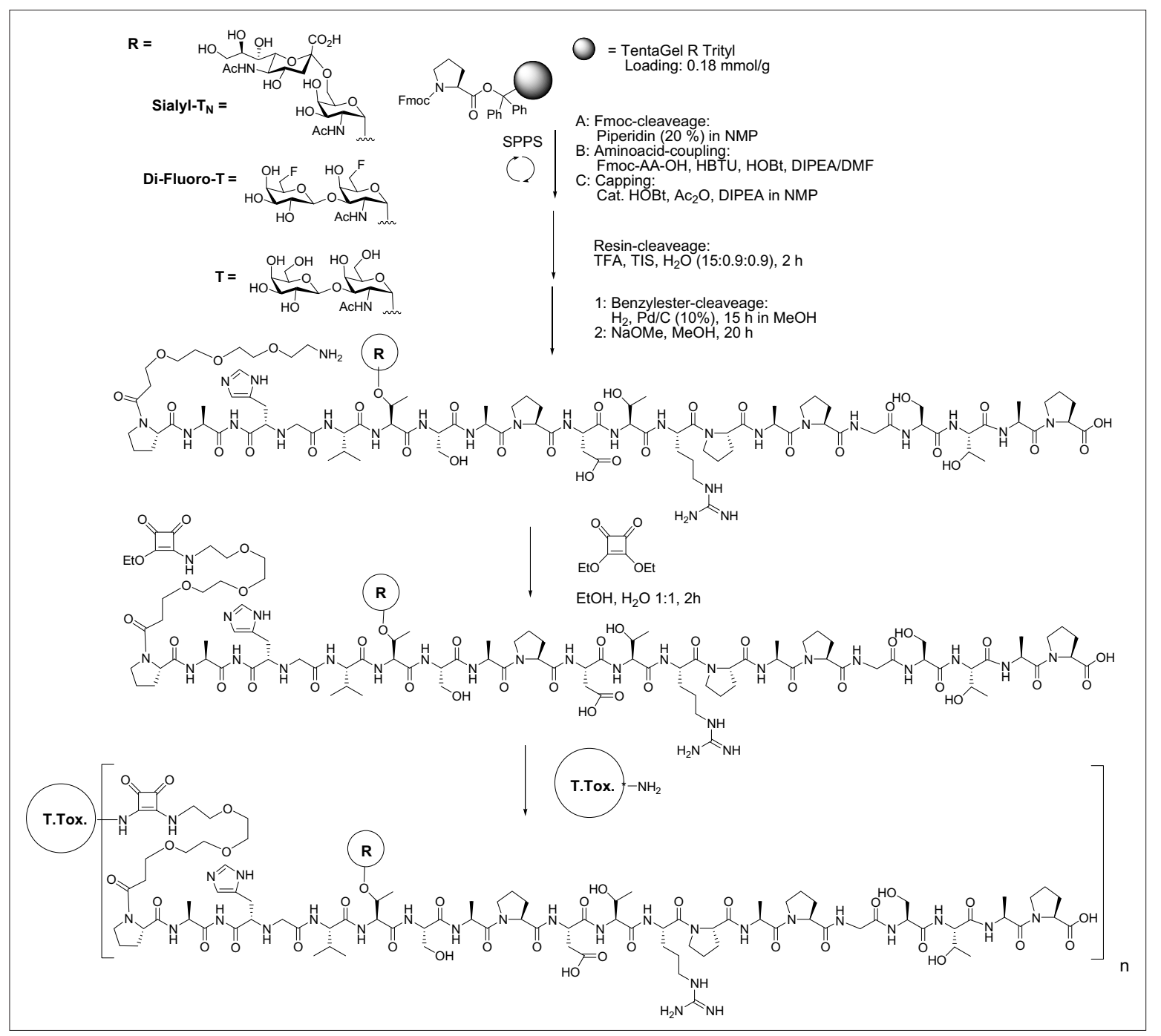

Scheme 1. Example of the synthesis of Tetanus Toxoid protein conjugate vaccines.

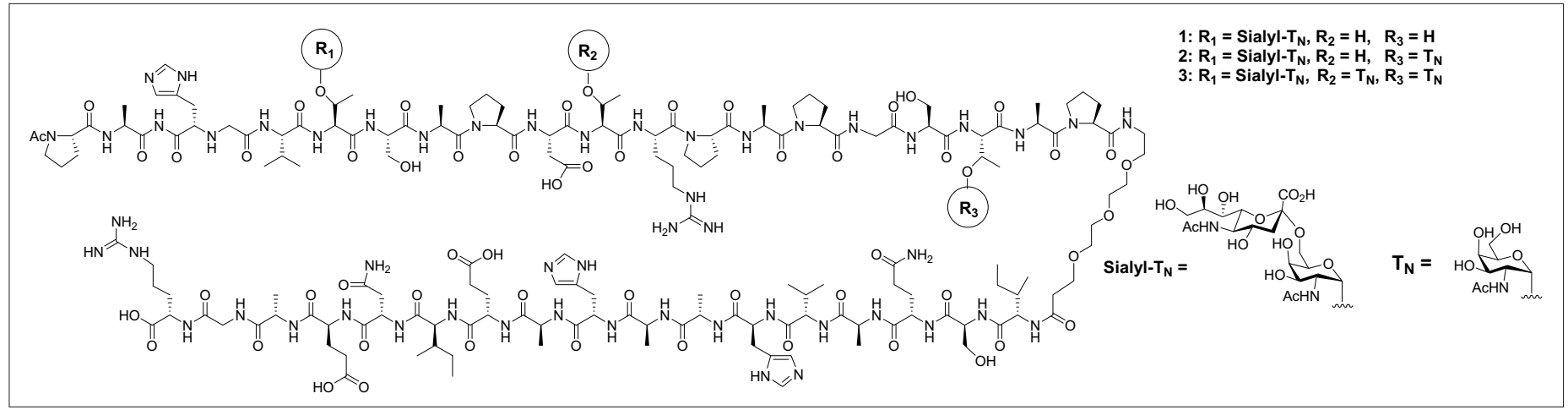

Fig. 3. MUC1-OVA ${ }_{323-339}$ T-cell epitope glycopeptide vaccines.

gates are well-established. Common for all preparations of these conjugates is that the MUC1 glycopeptide must be completely deprotected before coupling to the carrier protein. Immunizations with MUC1 glycopeptides coupled through diethyl squarate to Tetanus Toxoid as an immune carrier have recently shown promising results including in humans. ${ }^{[11]}$ MUC1 glycopeptides containing a sialyl- $T_{N} 4$, a T-antigen 5 or a di-fluoro-T-antigen 6 MUC1 glycopeptide equipped with an oligoethylene glycol spacer amino acid were conjugated to Tetanus Toxoid protein employing diethyl squarate (3,4-diethoxy-3-cyclobutene-1,2-dione) as the coupling reagent. ${ }^{[11]}$ (Scheme 1 and Fig. 4). Immunological evaluation of these vaccines showed that very strong immune responses were induced in almost all of the immunized mice, with antibodies elicited towards the MUC1 antigens present in the vaccines. The binding of antibodies induced by the T-antigen vaccines $\mathbf{5}$ and $\mathbf{6}$ to tumor cells was also evaluated by FACS analysis. It was shown that the antibodies recognize MCF-7 breast cancer cells (Fig. 4).

It appears attractive to prepare vaccines targeting more than one tumor-associated epitope at the same time during the immunization. This can be achieved by combining vaccines targeting different tumor-associated saccharide antigens on the peptide backbone like $\mathrm{T}_{\mathrm{N}}$, sialyl- $\mathrm{T}_{\mathrm{N}}, \mathrm{T}$ and sialyl- $\mathrm{T}$ structures or by combining vaccines with variation of the position for glycosylation on the MUC1 tandem repeat. A problem of immunizations with combined vaccines containing different antigens separately conjugated to the carrier protein, could be the risk that the increased levels of carrier protein like KLH will lead to decreased immunogenicity of the individual antigens. 


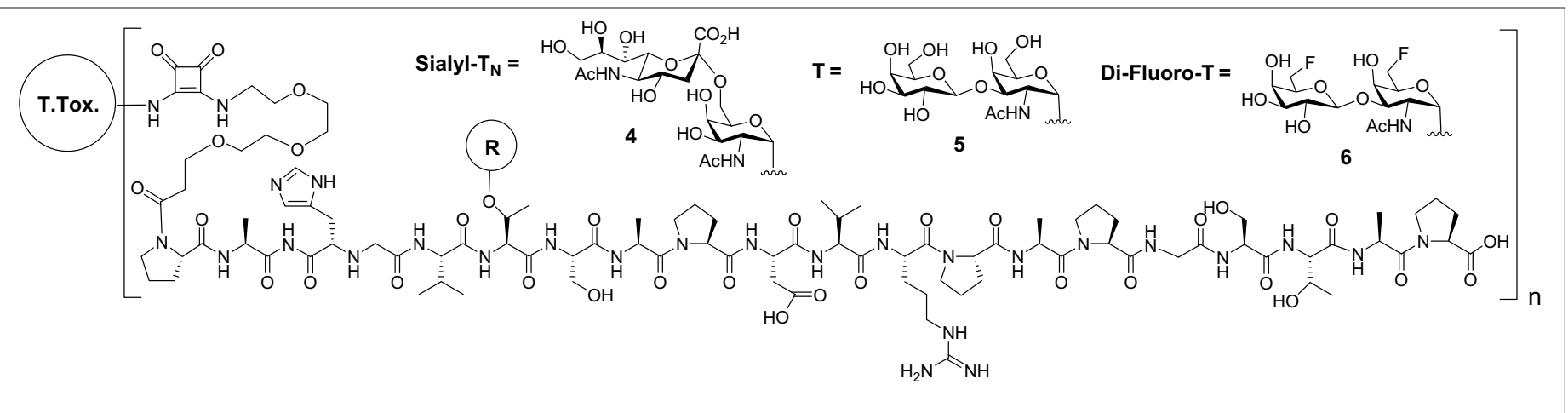

Fig. 4. MUC1-Tetanus Toxoid glycopeptide vaccines.

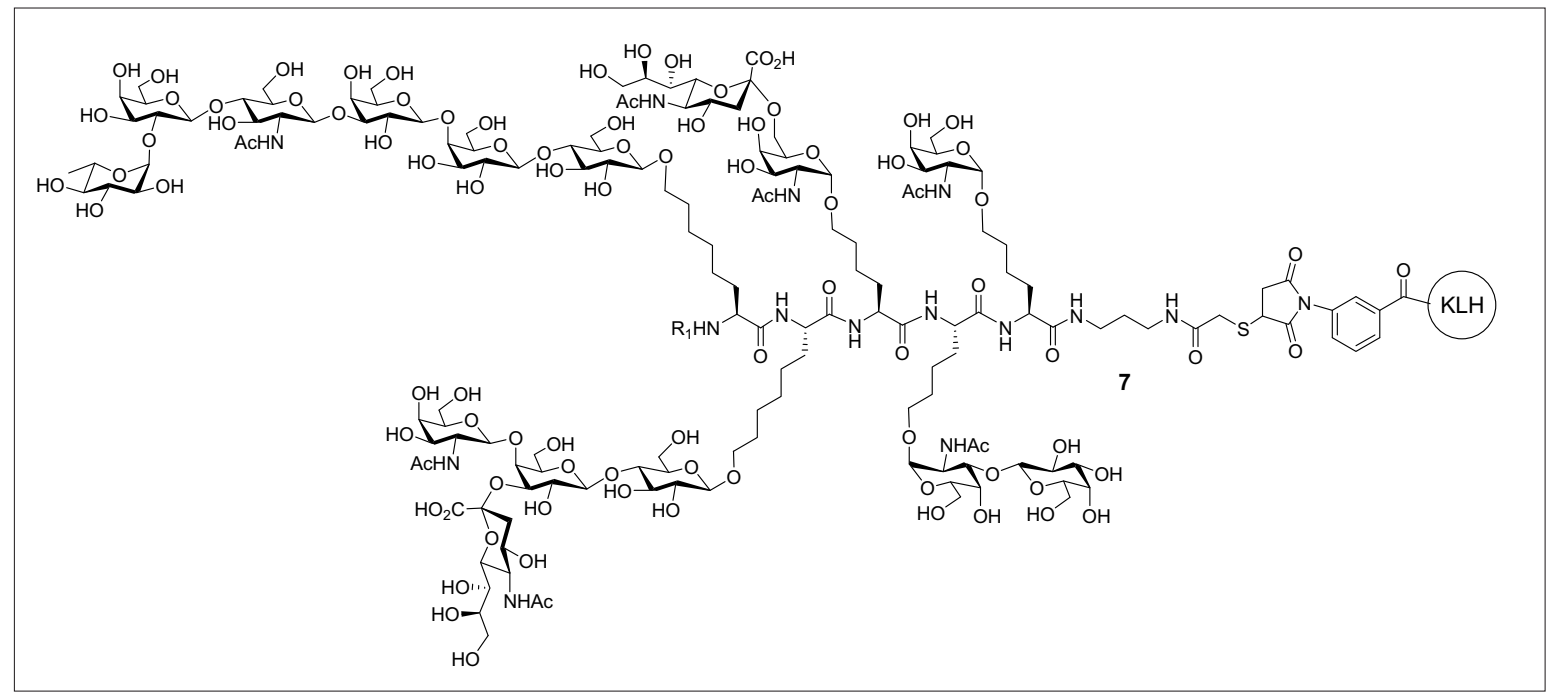

Fig. 5. Hybrid glycopeptide KLH conjugate vaccines.

To avoid this effect, an unimolecular multiepitope vaccine was used.[13] Hybrid glycopeptide KLH conjugate vaccines were prepared based on a mixture of tumor-associated glycans linked through spacers to the peptide backbone. Both tumor-associated glycolipid glycans like Globo-H, GM2 and glycoprotein glycans like $\mathrm{T}_{\mathrm{N}}$, sialyl- $\mathrm{T}_{\mathrm{N}}, \mathrm{T}$ were combined in the vaccine (Fig 5.) The prepared vaccine construct 7 was injected in mice. ELISA analysis of the mice sera showed that both IgG and IgM antibodies were generated specifically recognizing each individual carbohydrate antigen. Additional FACS analysis showed that MCF-7 breast cancer cells were recognized by the sera. However, it was revealed that exclusively antibodies of the short-lived IgM type were responsible for this binding recognition (Fig. 5).

\section{MUC1 Glycopeptides Containing a Built-in Adjuvant}

Adjuvants are typical immunostimulants, which consist of characteristic molecular patterns derived from pathogens to which the immune system is commonly pre-exposed. An example of a MUC1 glycopeptide vaccine conjugated to both an immuno adjuvant and T-cell epitope will be described here.[14] The adjuvant used, $S$-[(R)-2,3-dipalmitoyloxy-propyl]$N$-palmitoyl- $(R)$-cysteine $\quad\left(\mathrm{Pam}_{3} \mathrm{Cys}\right),{ }^{[15]}$ is a ligand of the Toll-like receptor 2 . Through interaction with the receptor, proinflammatory cytokines and chemokines are produced, which stimulate the APCs to process and present the immunogenic epitopes contained in the vaccine to the Tcells. The lipopeptide structure $\mathrm{Pam}_{3} \mathrm{Cys}$ also facilitates the formation of liposomes, which serve as efficient vaccine delivery vehicles. An example of $\mathrm{Pam}_{3} \mathrm{Cys}$ adjuvant vaccines is a three-component vaccine containing a $\mathrm{T}_{\mathrm{H}}$-cell epitope of the peptide sequence 103-KLFAVWKITYKDT-115 derived from polio virus. The B-cell epitope consisted of a MUC1 decapeptide glycosylated with a GalNAc residue $\left(T_{N}\right.$ antigen) in the immunodominant domain. This construct was generated by a native chemical ligation (NCL) based approach combining the $\mathrm{Pam}_{3}$ Cys adjuvant with the two B- and T-cell epitope peptides. The $\mathrm{T}_{\mathrm{N}}$ MUC1-polio $_{103-115}$ Pam $_{3}$ Cys three-component vaccine $\mathbf{8}$ was incorporated into phospholipid based liposomes and injected in mice. A high IgG immune response was detected. These antibodies also showed reactivity against the MUC1 specific breast cancer tumor cell line (MCF-7) according to FACS analysis (Fig. 6). Other examples of synthesized $\mathrm{Pam}_{3}$ Cys adjuvant vaccines are two-component vaccines containing the whole MUC1 tandem repeat glycosylated with Tn, T or 2,6-sialyl-T.[16]

\section{MUC1 Glycopeptide Dendrimer Vaccines}

By employing multi-epitope presentation based on a dendrimer, for example an oligo-lysine core, ${ }^{[17]}$ carrier-induced immune suppression, which can occur during immunization with carrier protein vaccines, could be avoided. Vaccines based on multiple antigen presentation are also considered favorable for the uptake and presentation of the antigen by antigen presenting cells (APCs). Synthesis of MUC1 and MUC4 $\mathrm{T}_{\mathrm{N}}$ and sialyl $\mathrm{T}_{\mathrm{N}}$ glycopeptide dendrimer vaccines were recently reported. ${ }^{[18]}$ One of these is MUC1 sialyl $\mathrm{T}_{\mathrm{N}}$ glycopeptide dendrimer vaccine $\mathbf{1 2}$ based on a di-lysyl lysine core. The vaccine was prepared both with and without an extra immunostimulating Tetanus Toxoid T-cell peptide epitope. These synthetic dendrimer vaccines are under investigation in immunization studies (Fig. 7). 


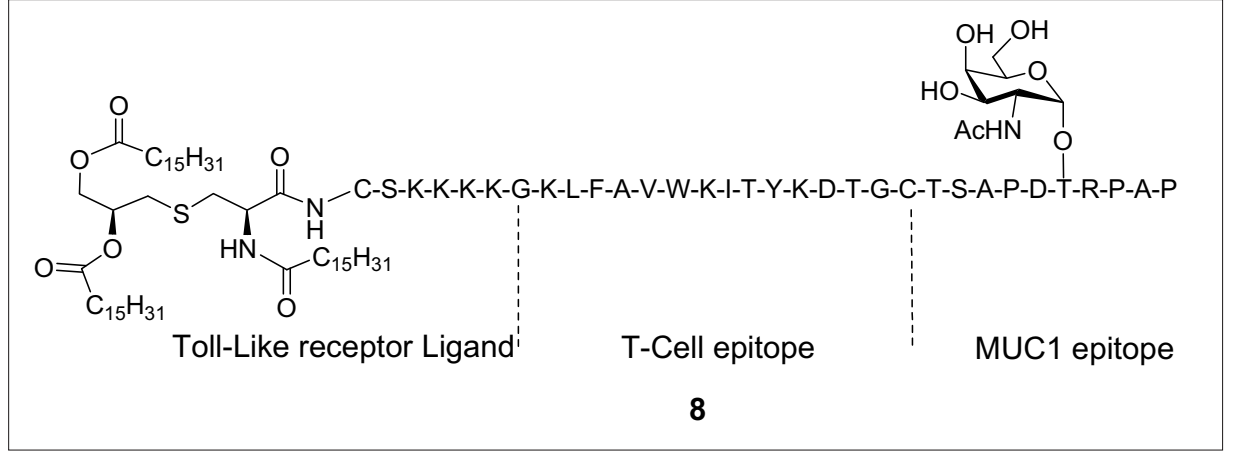

Fig 6. $T_{N}$ MUC1-polio103-115 Pam3Cys three-component vaccine.

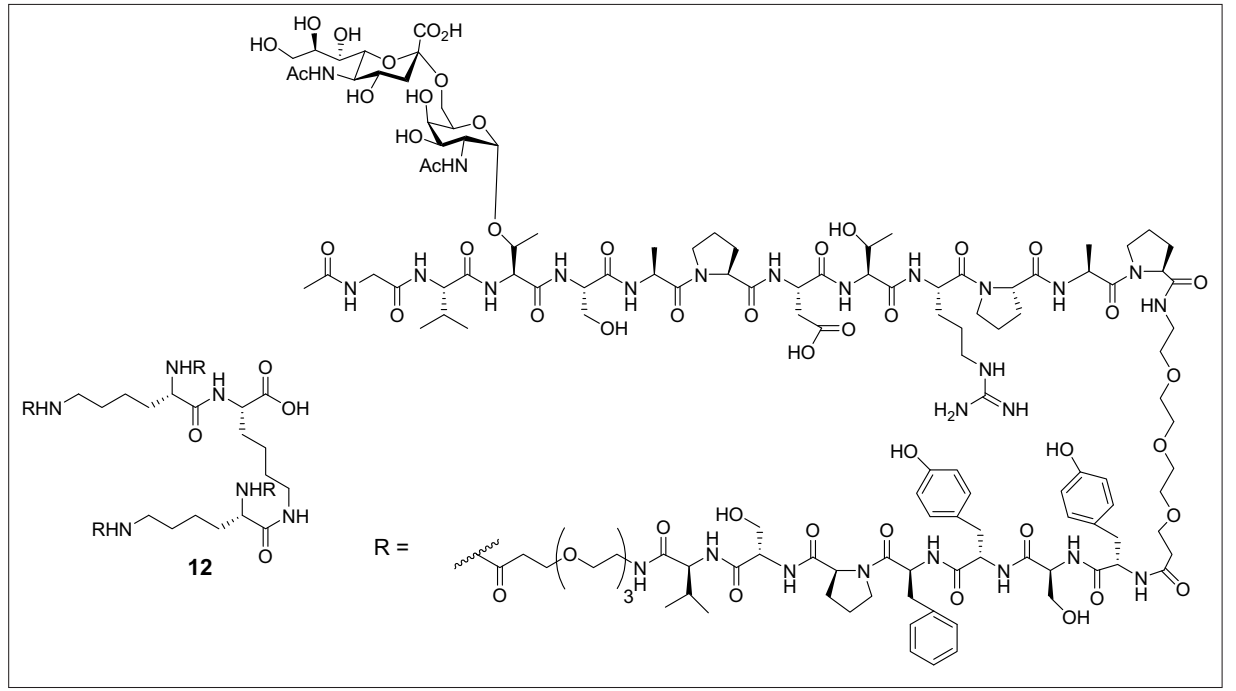

Fig. 7. Sialyl- $T_{N}$ MUC1 oligo-lysine dendrimer vaccine.

\section{Conclusions}

A number of tumor-associated MUC1 glycopeptides based on the $\mathrm{T}_{\mathrm{N}}, \mathrm{T}$, sialyl- $\mathrm{T}_{\mathrm{N}}$ and sialyl-T structures have been synthesized and conjugated to various immune stimulants. Immunological evaluation of these vaccines has shown that glycopeptide specific antibodies and antibodies recognizing cancer cells are generated from a number of these vaccines. In particular, the MUC1 Tetanus Toxid vaccines are promising. They generally induce very strong immune responses which override the natural tolerance of the immune system. The induced antibodies of the IgG type specifically bind to epithelial tumor cells, such as the MCF-7 breast cancer cells. Tetanus Toxoid-based vaccines have already been proven to be applicable in humans.

Received: October 29, 2010

[1] G. F. Springer, Science 1984, 224, 1198.

[2] a) J. Taylor-Papadimitriou, J. Burchell, D. W. Miles, M. Dalziel, Biochim. Biophys. Acta, Mol. Basis Dis. 1999, 1455, 301; b) F.-G. Hanisch, Biol. Chem. 2001, 382, 143.

[3] D. M. Swallow, S. Gendler, B. Griffiths, G. Corney, J. Taylor-Papadimitriou, M. E. Bramwell, Nature 1987, 328, 82.

[4] a) I. Brockhausen, J.-M. Yang, J. Bruchell, C. Whitehouse, J. Taylor-Papadimitriou, Eur. J.
Biochem. 1995, 233, 607; b) I. Brockhausen, Biochim. Biophys. Acta, Gen. Subj. 1999, 1473, 67; c) J. M. Burchell, A. Mungul, J. Taylor-Papadimitriou, $J$ Mammary Gland Biol. Neoplasia 2001, 6, 355; d) K. O. Lloyd, J. Burchell, V. Kudryashov, B. W. T. Yin, J. Taylor-Papadimitriou, J. Biol. Chem. 1996, 271, 33325.

[5] R. N. Germain, Cell 1994, 76, 287.

[6] a) T. Becker, S. Dziadek, S. Wittrock, H. Kunz, Curr. Cancer Drug Targets 2006, 6, 491; b) A. Liakatos, H. Kunz, Curr. Opin. Mol. Ther. 2007, 9,35 .

[7] S. Ingale, M. A. Wolfert, J. Gaekwad, T. Buskas, G.-J. Boons, Nature Chem. Bio. 2007, 3, 663.

[8] a) J. M. J. Frechet, K. E. Haque, Tetrahedron Lett. 1975, 116, 3055; b) M. Wagner, S. Dziadek, H. Kunz, Chem. Eur. J. 2003, 9, 6018; c) O. Seitz, H. Kunz, J. Org. Chem. 1997, 62, 813; d) S.-S. Wang, J. Am. Chem. Soc. 1973, 95, 1328.

[9] a) L. A. Carpino, J. Am. Chem. Soc. 1993, 115, 4397; b) V. Dourtoglou, B. Gross, V. Lambropoulou, C. Zioudrou, Synthesis 1984, 572.

[10] a) S. Peters, T. Bielfeldt, M. Meldal, K. Bock, H. Paulsen, J. Chem. Soc., Perkin Trans. 1 1992, 1163; b) A. M. Jansson, M. Meldal, K. Bock, J. Chem. Soc., Perkin Trans. 1 1992, 1699; c) H. Kunz, S. Birnbach, P. Wernig, Carbohydr. Res. 1990, 202, 207; d) E. Bardaji, J. L. Torres, P. Clapes, F. Albericio, G. Barany, R. E. Rodriguez, J. Chem. Soc., Perkin Trans. 1 1991, 1755.

[11] a) A. Kaiser, N. Gaidzik, U. Westerlind, D. Kowalczyk, A. Hobel, E. Schmitt, H. Kunz, Angew. Chem., Int. Ed. 2009, 48, 7551; b) A. Hoffman-Röder, A. Kaiser, S. Wagner, N.
Gaidzik, D. Kowalczyk, U. Westerlind, B. Gerlitzki, E. Schmitt, H. Kunz, Angew. Chem. Int. Ed. 2010, 49, in press.

[12] a) U. Westerlind, A. Hobel, N. Gaidzik, E Schmitt, H. Kunz, Angew. Chem. Int. Ed. 2008 47, 7551; b) U. Westerlind, H. Schröder, A. Hobel, N. Gaidzik, A. Kaiser, C. M. Niemeyer, E. Schmitt, H. Waldmann, H. Kunz, Angew. Chem., Int. Ed. 2009, 48, 8263.

[13] a) J. Zhu, C. Wan, D. Lee, G. Yang, M. Spassova, O. Ouerfelli, G. Ragupathi, P. Damani, P. Livingstone, S. J. Danishefsky, J. Am. Chem. Soc. 2009, 131, 9298; b) G. Ragupathi, F. Koide, P. Livingstone, Y. S. Cho, A. Endo, C. Wan, M. Spassova, S. Keding, J. Allen, O. Ouerfelli, R. Wilson, S. J. Danishefsky, J. Am. Chem. Soc. 2006, 128, 2715; c) D. Lee, S. J. Danishefsky, Tetrahedron Lett. 2009, 50, 2167.

[14] a) S. Ingale, M. A. Wolfert, T. Buskas, G.-J. Boons, ChemBioChem 2009, 10, 455; b) S. Ingale, M. A. Wolfert, J. Gaekwad, T. Buskas, G.-J. Boons, Nat. Chem. Biol. 2007, 3, 663; c) S. Ingale, T. Buskas, G.-J. Boons, Org. Lett. 2006, 8, 5785.

[15] W. G. Bessler, L. Heinewetter, K. H. Wiesmueller, G. Jung, W. Baier, M. Huber, A. R. Lorenz, U. V. D. Esche, K. Mittenbuehler, P. Hoffman, Int. J. Immunopharmacol. 1998, 19, 547.

[16] A. Kaiser, N. Gaidzik, T. Becker, C. Menge, K Groh, H. Cai, Y.-M. Li, B. Gerlitzki, E. Schmitt, H. Kunz, Angew. Chem. 2010, 122, 3772; Angew. Chem. Int. Ed. 2010, 49, 3688.

[17] J. P. Tam, Proc. Natl. Acad. Sci. 1988, 85, 5409.

[18] a) T. Becker, A. Kaiser, H. Kunz, Synthesis 2009, 1113; b) S. Keil, A. Kaiser, F. Syed, H. Kunz, Synthesis 2009, 1355. 